\title{
Effects of Cooling Conditions on Microstructure and Mechanical Properties of Friction Stir Welded Butt Joints of Different Aluminum Alloys
}

\author{
Sara Bocchi ${ }^{\circledR}$, Gianluca D’Urso *, Claudio Giardini ${ }^{\circledR}$ and Giancarlo Maccarini \\ Department of Management, Information and Production Engineering, University of Bergamo, 24044 Dalmine, \\ Italy; sara.bocchi@unibg.it (S.B.); claudio.giardini@unibg.it (C.G.); giancarlo.maccarini@unibg.it (G.M.) \\ * Correspondence: gianluca.d-urso@unibg.it; Tel.: +39-035-205-2330
}

Received: 18 October 2019; Accepted: 22 November 2019; Published: 24 November 2019

Featured Application: This work is aimed at the optimization of the friction stir welded joint with particular attention to the specific material and the specific application of the welded product in order to widely implement this technology in the industrial field.

\begin{abstract}
The aim of this work is to evaluate the difference between the properties of several aluminum alloy joints welded with the traditional air-cooled friction stir welding process and others obtained by the combination of the traditional friction stir welding setup with a water-cooling system. In particular, precipitation-hardening alloys AA2024-T3, AA6082-T6 and AA7075-T6, and a work-hardening alloy, AA5754-H111, were taken into account. From Rockwell and Vickers hardness maps, it was possible to observe a clear dependence of the hardness distribution on the cooling systems; joints obtained using a water-cooling system showed higher values of hardness, reached in the central zone and a narrow area interested by the hardness reduction for all the tested alloys. From tensile tests executed orthogonally to the welding direction, it was possible to observe that the alloys have responded differently in terms of ultimate tensile strength and final elongation when the water-cooling system was used. The microstructural analysis of the three precipitation-hardening alloys showed a larger average grain size in the nugget zones for the water-cooled condition. Moreover, in the thermo-mechanically altered zones of the water-cooled AA6082 and AA7075 joints, the grains were characterized by a smaller average size than the grains of the same air-cooled welds.
\end{abstract}

Keywords: friction stir welding; aluminum alloys; precipitation-hardening alloy; work-hardening alloy; water-cooling system

\section{Introduction}

Aluminum has proven to be a material of considerable interest in engineering, especially in the aeronautic and automotive sectors, because of its advantageous ratio between mechanical properties and weight. Significant importance in these fields is assumed by the aluminum precipitation-hardening alloys, which can achieve mechanical properties comparable to those of structural steel [1,2].

The precipitation-hardening mechanism is based on the reduction of the solubility of the alloying elements, which occurs from high temperatures to room temperature [3]. By carrying out a solubilization quench, that is moving in the solubility field with sudden cooling, the dispersion of the alloy elements is obtained in the form of clusters. Subsequently, these clusters split up to give nano-metric precipitates dispersed in the matrix that allow these alloys to reach the mechanical characteristics that distinguish them, by preventing the movement of the dislocations [4]. 
However, these alloys are characterized by a considerable difficulty in welding, since the achievement of the melting temperature leads to the elimination of this treatment and therefore to the rapid decline of the mechanical properties.

In fact, the high temperature reached in traditional welding techniques leads to the diffusion of the heat coming from the welding joint in the surrounding areas, creating a very wide heat affected zone characterized by an important microstructural alteration. These microstructure changes lead to an enlargement of the grains, responsible for the reduction of mechanical properties. Hall and Petch (H-P) have demonstrated that the strength of metallic materials increases when the grain size is smaller, as shown by this relationship [5]:

$$
\sigma_{y}=\sigma_{0}+k_{y} / \sqrt{d}
$$

where $\sigma_{\mathrm{y}}$ is the yield strength, $\sigma_{0}$ is a constant for the starting stress for dislocation movement and it depends on the material, $\mathrm{k}$ is H-P slope and $\mathrm{d}$ is the average grain diameter.

Furthermore, the heat-affected zone generated by a traditional welding technique is characterized by various types of defects and problems. For example, porosity can be generated due to any gas trapped during solidification, or inclusions of slag, such as oxides, remaining in the joint can make it very brittle. One of the most important welding problems consists of the hot or cold cracks generated during the weld solidification (due to the presence of impurities) or during the weld cooling (due to the residual stress generated by the hydrogen trapped in the joint).

For these reasons, over the years, numerous alternative welding technologies have been developed in order to reduce the amount of heat generated during the process, including Friction Stir Welding (FSW) [6].

Since FSW is a solid-state bonding technology, it is possible to weld together many and different materials obtaining a higher level of quality than that achieved with traditional welding techniques [7-9]. In fact, in the FSW joints, the porosity is very low and there is no formation of cracks, due to the limited contribution of the heat generated during the process. Finally, this limited thermal flux leads to an important reduction of the residual stress state of the welded joints and of the distortions of the final products [10].

The FSW uses the rotating action of a tool, called a pin, which is interposed between two sheets to be joined. The mechanical action of the pin leads to mixing of the plasticized metal and to the achievement of a solid-state solution between the two sheets, so resulting in a considerable variation of the joint microstructure [11,12].

In the last decade, several research studies have been carried out to analyze the correlation between the friction stir welding process and the joint microstructure; this affects both the mechanical and metallurgical properties of the welded products [13-16]. With the aim of limiting these microstructural distortions inside the joint, other researchers have investigated the possibility of performing some post-welding heat treatments [15-19]. Indeed, better microstructural control would allow to obtain even better mechanical properties than those that can be already obtained from a traditional FSW process. In view of this, the recent development in this field of research is moving towards the development of friction stir process operations in which a cooling system is present to limit the effect of the thermal flux on the material during the welding process [20]. This type of system allows the control of the microstructure of the joints during the welding process, limiting the need for post-process heat treatments.

Several researchers have studied the response of a specific aluminum alloy to the cooling treatment during welding in the last years [21-25]. L. Fratini et al. [26] examined the mechanical and metallurgical effects of in-process cooling FSW of AA7075-T6 butt joints. W.F. Xu et al. [27] studied the FSW of thick AA2219 sheets considering air-cooling and water-cooling systems. Cho et al. [28] observed the effects of a cooling system combined with an FSW process on an extruded AA6082 billet. However, little has been done on the comparison of the effects of a water-cooling approach applied to a different series of aluminum alloys. 
In the present paper, both precipitation-hardening alloys (AA2024-T3, AA6082-T6 and AA7075-T6) and a work-hardening alloy (AA5754-H111) have been taken into consideration in order to evaluate the difference between the properties of the joints welded with traditional air-cooled FSW process and those obtained by combining a traditional FSW setup with a water-cooling system. The choice of the studied materials fell on these aluminum alloys, as they are the most used in the industrial field.

The research aims to investigate the effects of a water-cooling system on the mechanical properties and the microstructural characteristics of the joints for all the alloys studied in order to compare the effects and to identify the optimal working conditions for each material.

\section{Materials and Methods}

The chemical composition and the mechanical properties of the base aluminum alloys used in the experimental procedure are reported in Tables 1 and 2.

Table 1. Chemical composition (\% weight) of the base materials.

\begin{tabular}{cccccccccc}
\hline Alloy & Al & Si & Fe & Cu & Mn & Mg & Zn & Ti & Cr \\
\hline AA2024-T3 & bulk & 0.06 & 0.09 & 4.50 & 0.46 & 1.40 & 0.08 & 0.04 & 0.03 \\
\hline AA6082-T6 & bulk & 0.9 & 0.36 & 0.07 & 0.42 & 0.8 & 0.05 & 0.03 & 0.02 \\
\hline AA7075-T6 & bulk & 0.05 & 0.10 & 1.53 & 0.008 & 2.54 & 5.72 & 0.04 & 0.20 \\
\hline AA5754-H111 & bulk & 0.103 & 0.34 & 0.059 & 0.318 & 2.808 & 0.019 & 0.009 & 0.019 \\
\hline
\end{tabular}

Table 2. Mechanical properties of the base materials.

\begin{tabular}{cccc}
\hline Alloy & $\begin{array}{c}\text { Yield Strength (YS) } \\
\text { [MPa] }\end{array}$ & $\begin{array}{c}\text { Ultimate Tensile } \\
\text { Strength (UTS) [MPa] }\end{array}$ & Max strain [\%] \\
\hline AA2024-T3 & 344 & 464 & 16 \\
\hline AA6082-T6 & 281 & 326 & 16 \\
\hline AA7075-T6 & 512 & 576 & 13.5 \\
\hline AA5754-H111 & 84 & 212 & 25.9 \\
\hline
\end{tabular}

Both air-cooled and water-cooled FSW tests were carried out for each material on $200 \times 80 \times 4 \mathrm{~mm}$ sheets using a FAMUP MC60 CNC machine equipped with a suitable tool for the Friction Stir Welding. The tool was characterized by a smooth flat shoulder ( $16 \mathrm{~mm}$ diameter) and a frustum of cone pin (maximum and minimum diameters equal to 6 and $4 \mathrm{~mm}$, height equal to $3.8 \mathrm{~mm}$ ) (Figure 1).

Due to the considerable forces generated during an FSW welding, it was necessary to fix the sheets to be welded on a support plate through 6 grips, as reported in Figure 2.

The welding parameters have been defined through a detailed bibliographic analysis, to obtain the best combination of rotational speed and feed rate for each alloy maximizing the mechanical characteristics of the welded joints [6,11,13,29-33].

Table 3 shows the parameters used in the experimental campaign.

To realize the water-cooled welded joints, a cooling system was appropriately designed and implemented, which allows a continuous and controlled flow of water at room temperature in the welding area. To ensure that no particles of water remain blocked in the joint during the welding process, the water has been kept away from the not yet welded part of the sheets by the presence of a bulkhead fixed near the pin (Figure 3). 


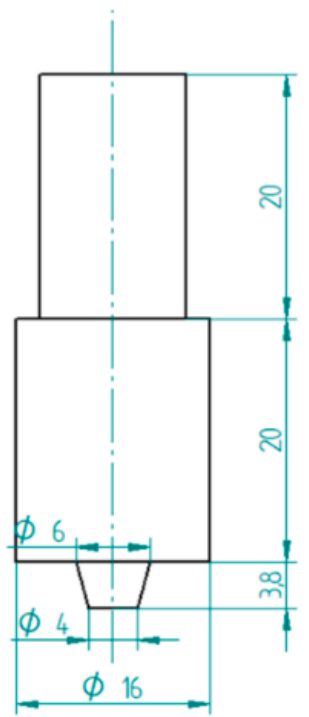

Figure 1. Friction Stir Welding (FSW) tool geometry.

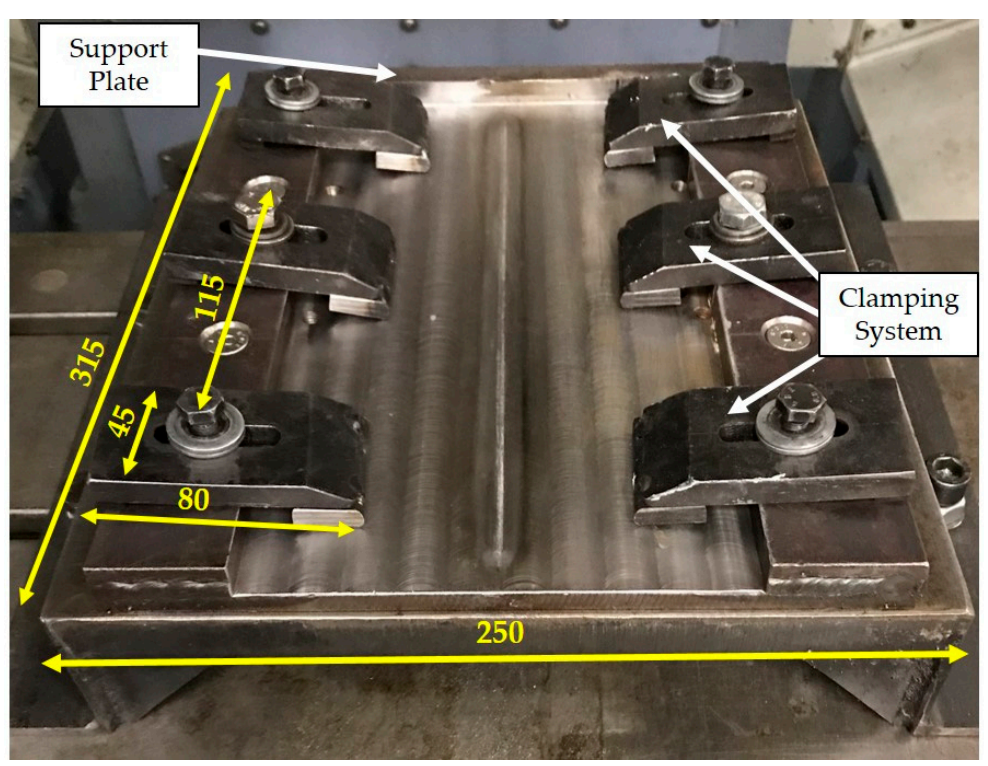

Figure 2. Support plate for the Friction Stir Welding (FSW) process.

Table 3. Parameters used for the experimental setup.

\begin{tabular}{ccccc}
\hline Aluminum Alloy & $\begin{array}{c}\text { Rotational Speed } \\
{[\mathrm{rad} / \mathrm{s}]}\end{array}$ & $\begin{array}{c}\text { Feed Rate } \\
{[\mathbf{m m} / \mathbf{m i n}]}\end{array}$ & $\begin{array}{c}\text { Tool } \\
\text { Inclination }\end{array}$ & $\begin{array}{c}\text { Tool Penetration Depth } \\
\text { into the Sheets [mm] }\end{array}$ \\
\hline AA2024-T3 & 125.7 & 100 & $3^{\circ}$ & 3.99 \\
\hline AA6082-T6 & 251.4 & 375 & $3^{\circ}$ & 3.99 \\
\hline AA7075-T6 & 157.1 & 40 & $3^{\circ}$ & 3.99 \\
\hline AA5754-H111 & 125.7 & 250 & $3^{\circ}$ & 3.99 \\
\hline
\end{tabular}




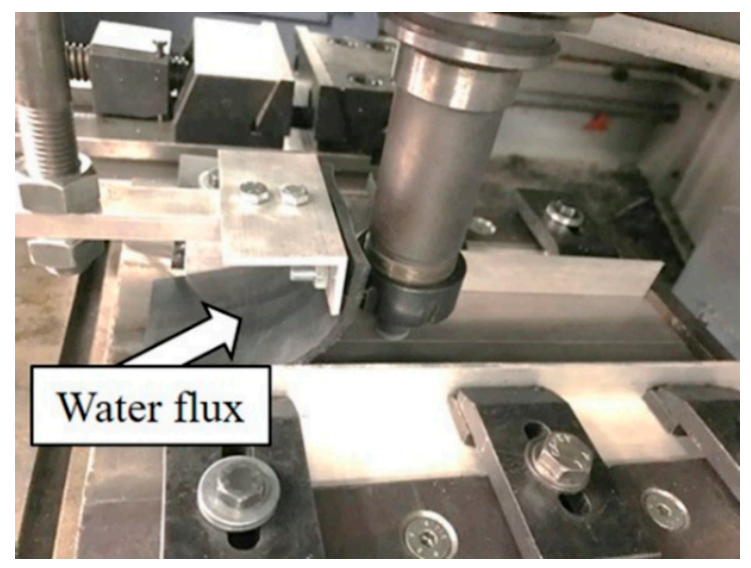

(a)

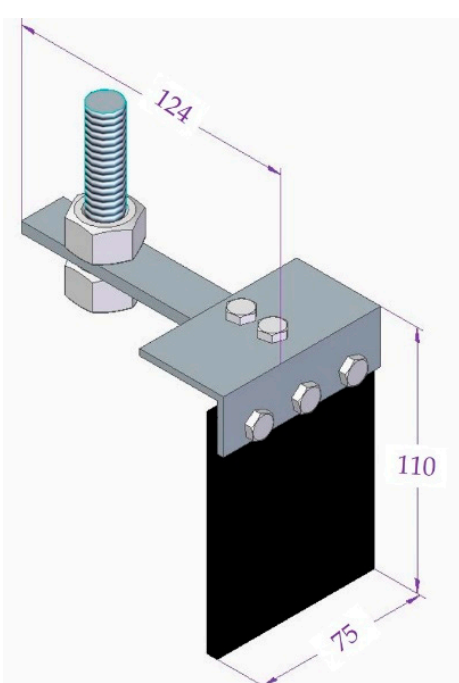

(b)

Figure 3. Water-cooling system (a) and detail of the bulkhead (b).

The samples were obtained by cutting the welded sheet in the rectangular area underlined in Figure 4, obtaining a $160 \times 20 \mathrm{~mm}$ sample, as shown in Figure 5 .

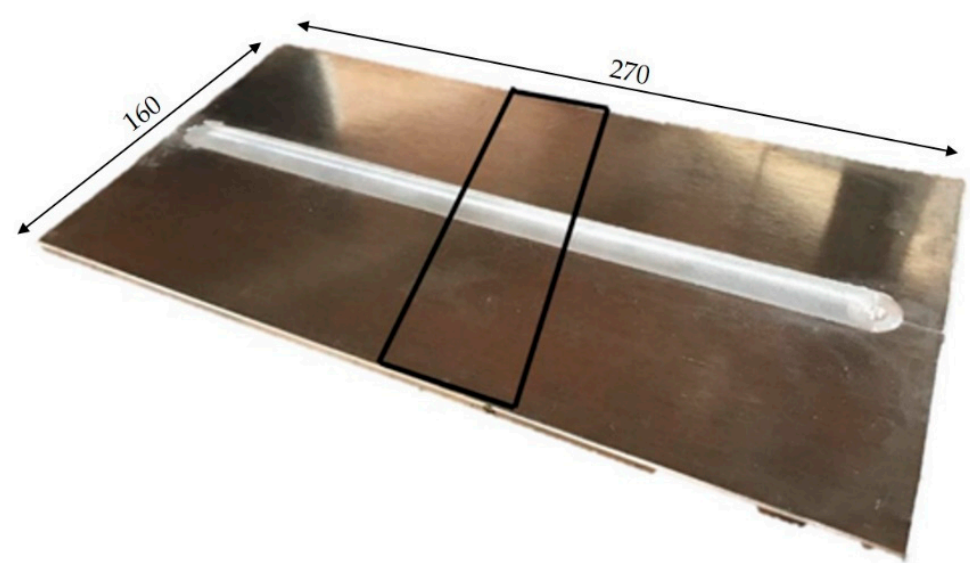

Figure 4. Part of the welded sheet on which the samples were cut out.

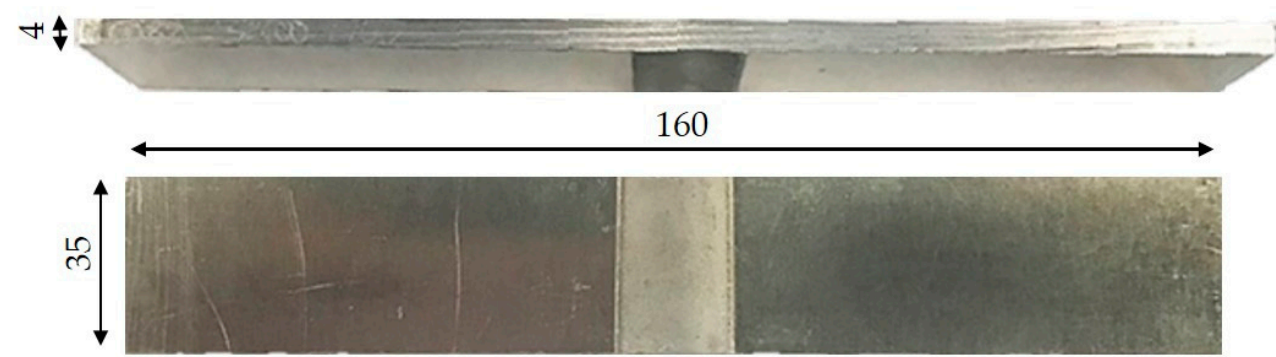

Figure 5. Appearance and morphology of a longitudinally cut Friction Stir Welded joint.

The mechanical characteristics of both air-cooled and water-cooled joints were evaluated by means of hardness and tensile tests of the joints.

The authors chose to perform the Vickers hardness tests on the cross-section of the specimen and the Rockwell hardness on the top surface of the specimens mainly due to the surface preparation requirements of the ASTM E92-17 standard for performing the Vickers test. In fact, in order to execute Vickers hardness tests, it is necessary to achieve a surface preparation that was not possible to obtain 
on the whole extension of the top of the samples $(160 \times 20 \mathrm{~mm})$. Therefore, the authors preferred to perform Rockwell hardness tests on the entire length of the specimens without losing the data relating to the outermost parts of the sample. Rockwell tests (HRB) were executed using a $5 \mathrm{~mm}$ spaced grid on the top of the specimen according to ISO 6508, while Vickers tests (HV) were executed using a $1 \mathrm{~mm}$ spaced grid on the transversal section of the specimen according to ASTM E92-17 and using a load of $1000 \mathrm{gf}$ to limit the elastic recovery of the material that could modify the measured values. Both hardness tests were carried out moving from the center of the welded joints until the hardness of the base material was reached.

Tensile tests (5 repetitions) were conducted according to UNI EN ISO 6892-1:2016 using a testing machine Galdabini with a load cell of $50 \mathrm{kN}$. The tests were carried out orthogonally to the welding direction, with the welding center placed in the middle of the specimen, according to EN 10002-1:2001, under speed control $(0.13 \mathrm{~mm} / \mathrm{s})$ and with a pre-load equal to $0.5 \mathrm{kN}$.

The microstructure of both the base materials and the cross-section specimens (Figure 5) was observed at the optical microscope only for precipitation-hardening alloys since on their microstructure the welding process is more damaging. The samples were mounted in a cold-working resin, polished up to $0.05 \mu \mathrm{m}$ with alumina suspension and etched by Keller (for AA2024 and AA7075) and Weck solutions (for AA6082). It is important to remark that all the tested specimens were extracted from a region of the welded sheet in which the steady state conditions of the process were achieved.

The average size of the grain in the base materials and also in correspondence of both the nugget and the Thermo Mechanically Altered Zones (TMAZs) was determined according to the Heyn lineal intercept procedure (ASTM E 112-13) on images obtained with an optical microscope with 400x magnification for the nugget and $200 \times$ for the TMAZs and for the base metals.

For each line drawn, the intercepted grain boundaries were counted and then the final average size of the single grain was calculated according to Equation (2).

$$
\begin{gathered}
d=A_{\text {int }} / M \\
A_{\text {int }}=l_{\text {line }} / n_{i}
\end{gathered}
$$

where:

$d$ : average grain diameter;

$A_{\text {int }}$ : average line length intersected;

$M$ : image magnification;

$l_{\text {line }}$ : length of the line;

$n_{i}$ : average numbers of grain boundaries intersected by the line.

To consider the anisotropy of the TMAZs, three lines of $300 \mathrm{~mm}$ parallel to the rolling direction and three lines of $200 \mathrm{~mm}$ perpendicular to the rolling direction were drawn. Due to the presence of equiaxial grains in the nugget zone, the evaluation of the average grain size in this zone was performed by tracing three parallel lines having a length equal to $100 \mathrm{~mm}$.

\section{Results}

\subsection{Microstructure Analysis}

The microstructures of AA2024, AA6082, and AA7075 base metal are reported in Figure 6. 

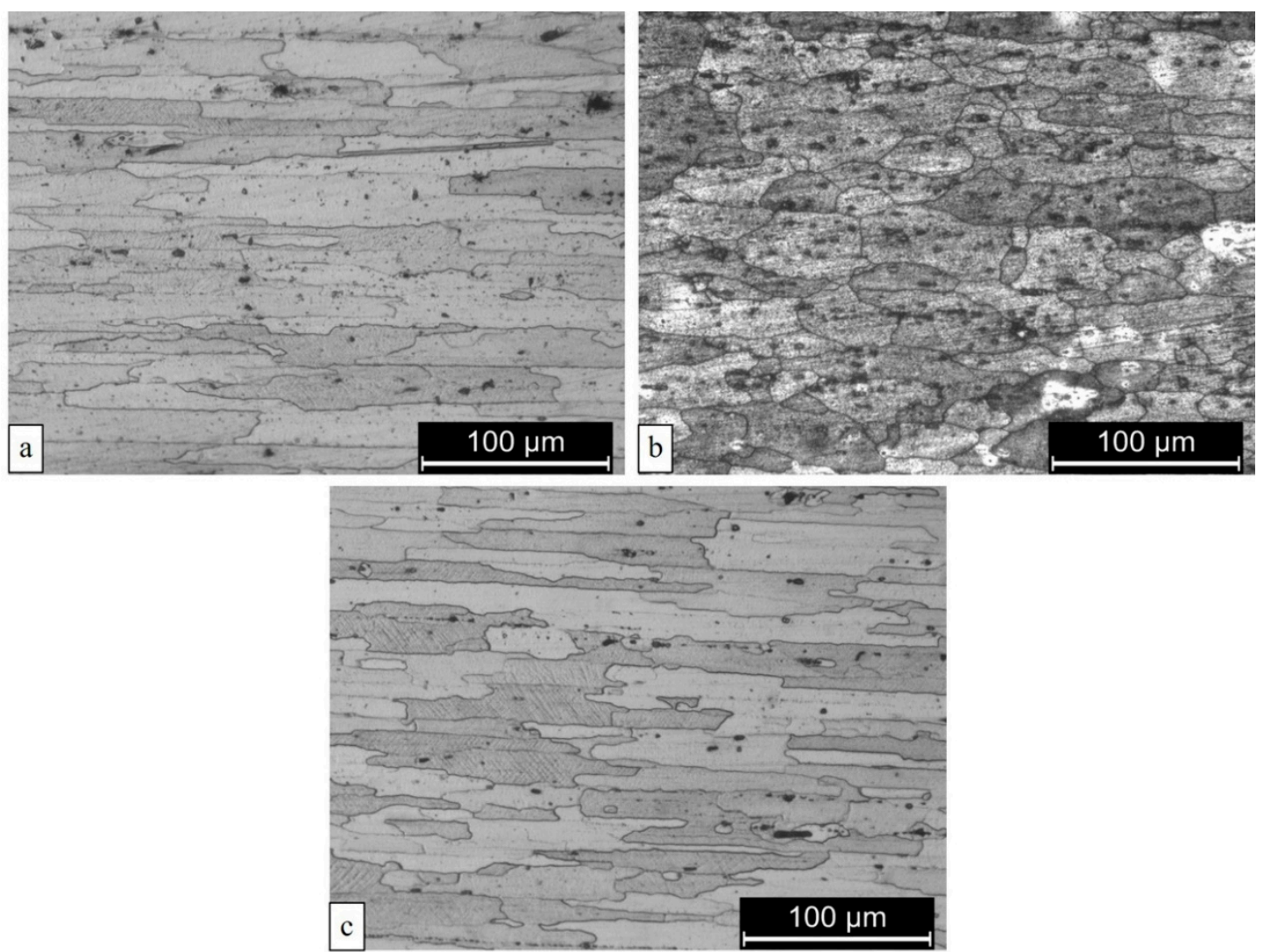

Figure 6. Microstructure of the base alloys: (a) AA2024, (b) AA6082, and (c) AA7075.

The microstructures of both nugget and TMAZs for AA2024, AA6082, and AA7075 under air-cooled and water-cooled conditions are reported in Figures 7-9. For all the alloys and for both the cooling conditions, it is possible to detect the typical microstructure characterizing the friction stir welded joints. In particular, in the nugget (Figure 7a,b, Figure 8a,b and Figure 9a,b), fine and equiaxial grains are present due to the thermo-mechanical action of the pin, which causes the crushing of the elongated grain detectable along the rolling direction in the base alloy. At the same time, with the breaking of the grains, even the precipitates are crushed. These particles are responsible for the mechanism that causes the reinforcement in precipitation-hardening aluminum alloys. The smaller crushed precipitates are usually distributed preferentially on the grain boundary, weakening the structure of the nugget, since the reinforcing particles are no longer uniformly distributed.

On the contrary, in the TMAZ (Figure 7c,d, Figure $8 c, d$ and Figure $9 c, d$ ) the elongated grains in the rolling direction present in the base metal are still detectable, due to the lack of direct mixing and the limited amount of heat reaching the area.

As already stated, the grain size has been determined according to Heyn lineal intercept procedure (Figure 10). 

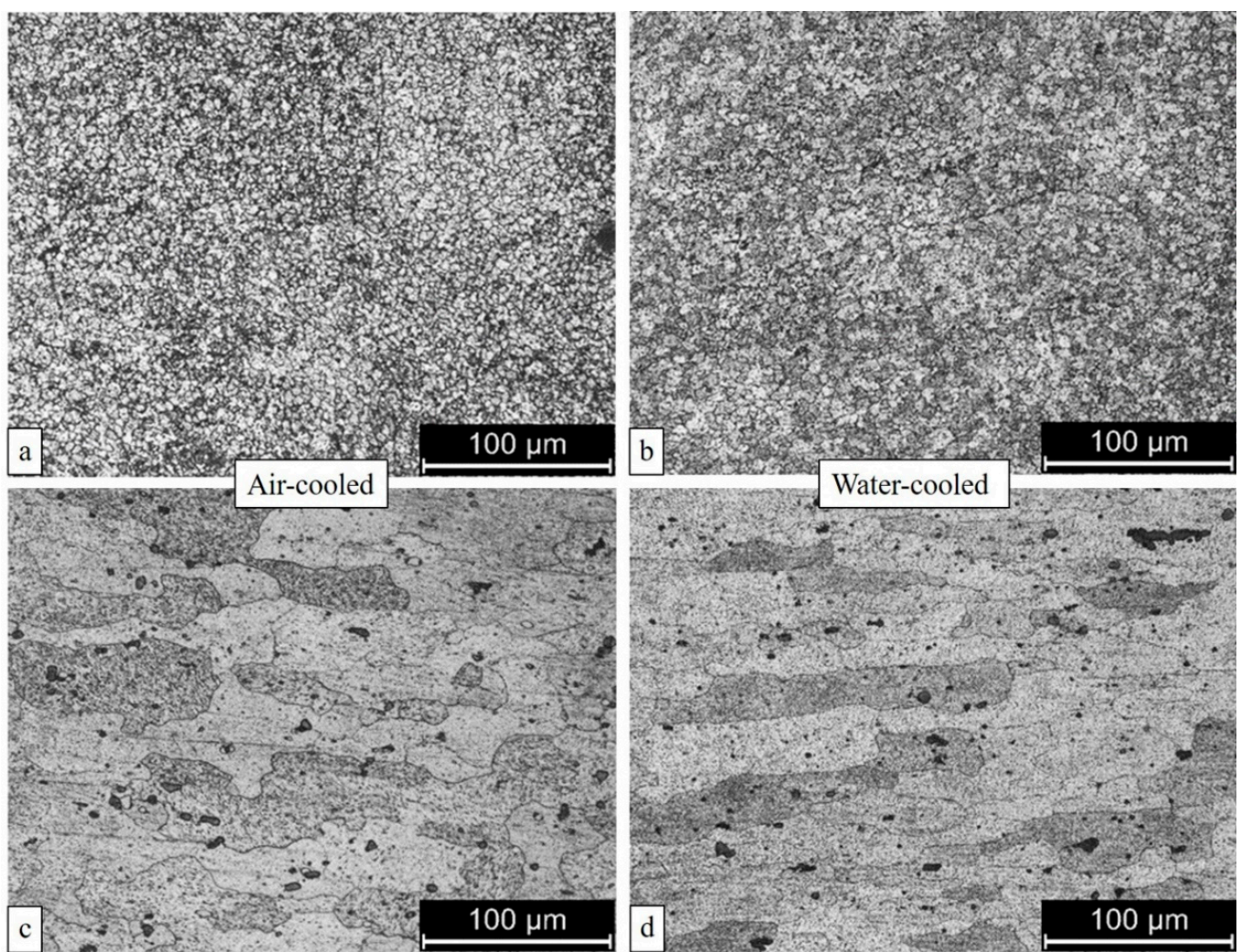

Figure 7. Microstructure of the nugget $(\mathbf{a}, \mathbf{b})$ and the Thermo Mechanically Altered Zones (TMAZ) (c,d) of AA2024 air-cooled (on the left) and water-cooled (on the right) welded joints.
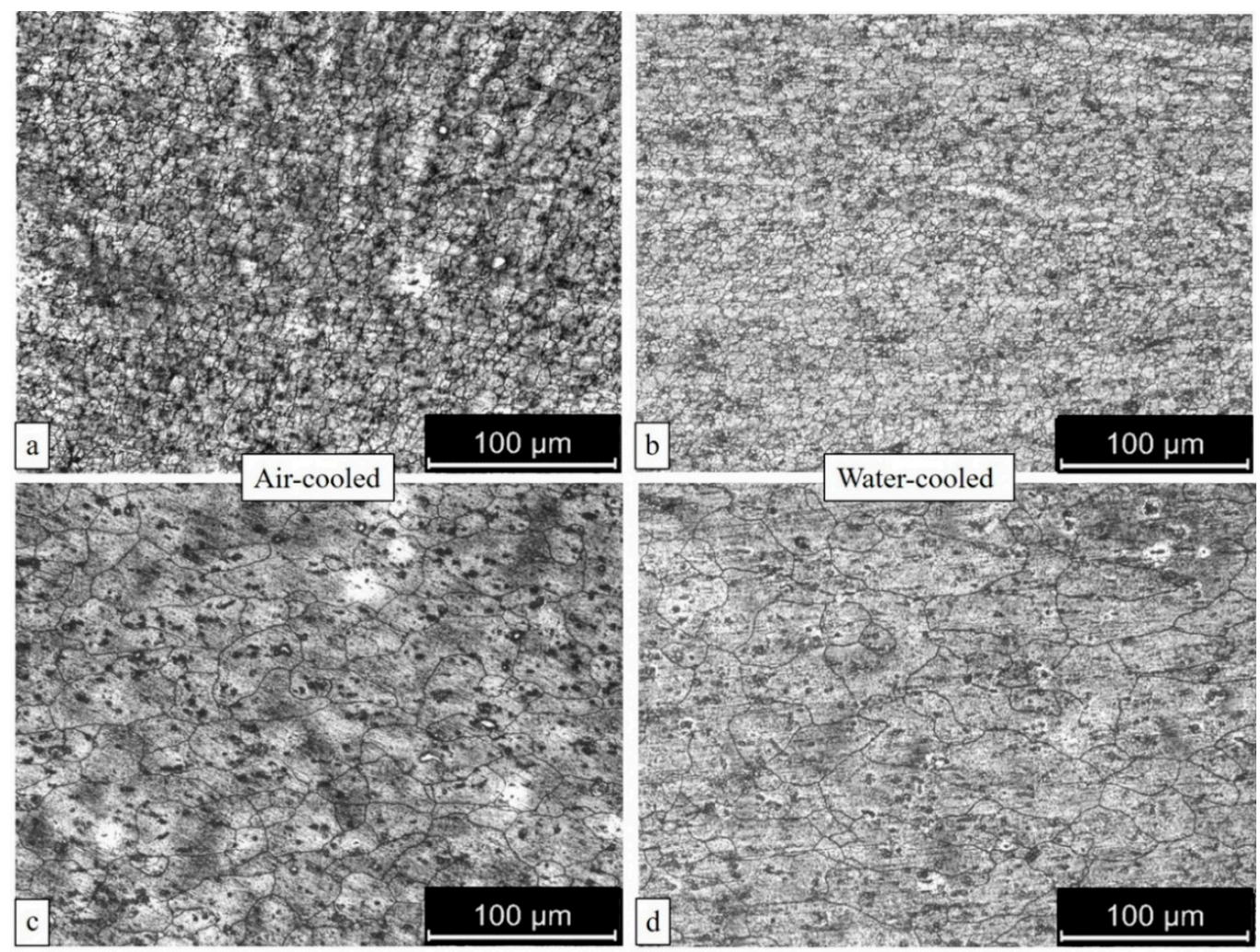

Figure 8. Microstructure of the nugget $(\mathbf{a}, \mathbf{b})$ and the Thermo Mechanically Altered Zones (TMAZ) (c,d) of AA6082 air-cooled (on the left) and water-cooled (on the right) welded joints. 

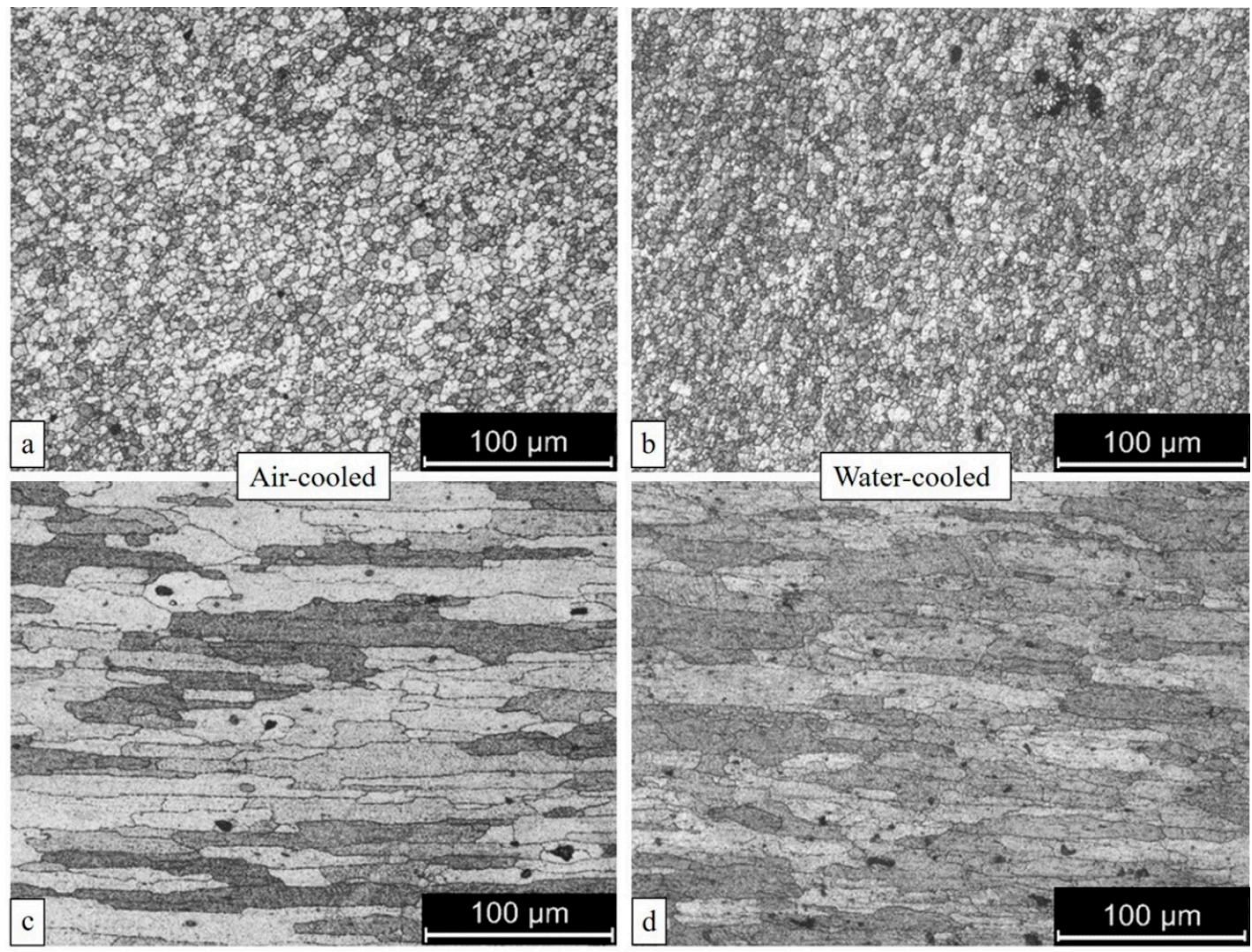

Figure 9. Microstructure of the nugget (a,b) and the TMAZ (c,d) of AA7075 air-cooled (on the left) and water-cooled (on the right) welded joints.

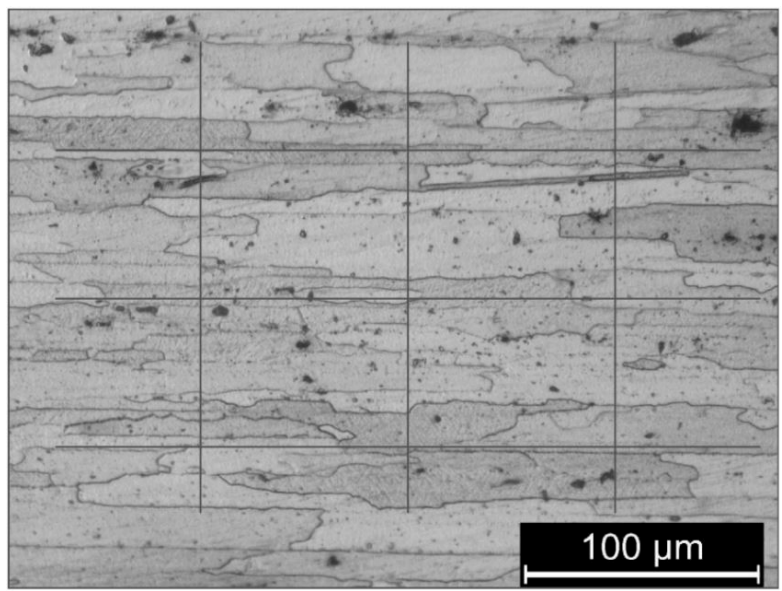

Figure 10. Example of the Heyn lineal intercept procedure.

For each line drawn, the intercepted grain boundaries were counted, and the results are reported in Table 4.

The average grains sizes in correspondence of both the nugget and the TMAZs for all the precipitation-hardening alloys and for both the cooling conditions are reported in Tables 5-7. 
Table 4. Counts of the grain boundary intersections with the drawn line for each alloy.

\begin{tabular}{|c|c|c|c|c|c|c|c|c|}
\hline \multicolumn{9}{|c|}{ AA2024 } \\
\hline & \multicolumn{2}{|c|}{ Base alloy } & \multicolumn{6}{|c|}{ FSW } \\
\hline & \multirow[b]{3}{*}{$/ /$} & \multirow[b]{3}{*}{$\perp$} & \multicolumn{3}{|c|}{ Air-cooled } & \multicolumn{3}{|c|}{ Water-cooled } \\
\hline & & & Nugget & \multicolumn{2}{|c|}{ TMAZ } & \multirow[t]{2}{*}{ Nugget } & \multicolumn{2}{|c|}{ TMAZ } \\
\hline & & & & $/ /$ & $\perp$ & & $/ /$ & $\perp$ \\
\hline Line 1 & 3 & 22 & 46 & 10 & 11 & 39 & 7 & 10 \\
\hline Line 2 & 6 & 19 & 45 & 12 & 11 & 38 & 9 & 18 \\
\hline \multirow[t]{6}{*}{ Line 3} & 4 & 16 & 44 & 9 & 11 & 41 & 11 & 19 \\
\hline & \multicolumn{8}{|c|}{ AA6082 } \\
\hline & \multicolumn{2}{|c|}{ Base alloy } & \multicolumn{6}{|c|}{ FSW } \\
\hline & & & \multicolumn{3}{|c|}{ Air-cooled } & \multicolumn{3}{|c|}{ Water-cooled } \\
\hline & & & Nugget & \multicolumn{2}{|c|}{ TMAZ } & Nugget & \multicolumn{2}{|c|}{ TMAZ } \\
\hline & // & $\perp$ & & $/ /$ & $\perp$ & & $/ /$ & $\perp$ \\
\hline Line 1 & 8 & 13 & 41 & 12 & 16 & 35 & 12 & 14 \\
\hline Line 2 & 9 & 16 & 51 & 12 & 18 & 37 & 13 & 12 \\
\hline \multirow[t]{6}{*}{ Line 3} & 11 & 14 & 44 & 10 & 16 & 30 & 14 & 13 \\
\hline & \multicolumn{8}{|c|}{ AA7075 } \\
\hline & \multicolumn{2}{|c|}{ Base alloy } & \multicolumn{6}{|c|}{ FSW } \\
\hline & & & \multicolumn{3}{|c|}{ Air-cooled } & \multicolumn{3}{|c|}{ Water-cooled } \\
\hline & & & \multirow[t]{2}{*}{ Nugget } & \multicolumn{2}{|c|}{ TMAZ } & Nugget & \multicolumn{2}{|c|}{ TMAZ } \\
\hline & // & $\perp$ & & $/ /$ & $\perp$ & & $/ /$ & $\perp$ \\
\hline Line 1 & 4 & 21 & 43 & 9 & 31 & 37 & 12 & 25 \\
\hline Line 2 & 6 & 20 & 36 & 13 & 25 & 35 & 17 & 26 \\
\hline Line 3 & 9 & 21 & 39 & 9 & 22 & 37 & 12 & 22 \\
\hline
\end{tabular}

Table 5. Average grain size in the base alloy, in the nugget and in the TMAZ of air-cooled and water-cooled AA2024 welds.

\begin{tabular}{|c|c|c|c|c|c|c|c|c|}
\hline & \multicolumn{8}{|c|}{ AA2024 } \\
\hline & \multicolumn{2}{|c|}{ Base alloy } & \multicolumn{6}{|c|}{ FSW } \\
\hline & & \multirow[b]{3}{*}{$\perp$} & \multicolumn{3}{|c|}{ Air-cooled } & \multicolumn{3}{|c|}{ Water-cooled } \\
\hline & \multirow[b]{2}{*}{$/ /$} & & Nugget & \multicolumn{2}{|c|}{ TMAZ } & \multirow[t]{2}{*}{ Nugget } & \multicolumn{2}{|c|}{ TMAZ } \\
\hline & & & & $/ /$ & $\perp$ & & $/ /$ & $\perp$ \\
\hline $\mathbf{n}_{\mathbf{i}}$ & 4.33 & 19 & 45.00 & 10.33 & 11.00 & 39.33 & 9.00 & 15.67 \\
\hline $\begin{array}{c}\mathrm{n}_{\mathbf{i}} \text { standard } \\
\text { deviation }\end{array}$ & 1.53 & 3 & 1 & 1.53 & 0 & 1.53 & 2 & 4.93 \\
\hline$A_{\text {int }}$ & 69.28 & 10.52 & 2.22 & 29.03 & 18.18 & 2.54 & 33.33 & 12.77 \\
\hline $\mathrm{d}[\mu \mathrm{m}]$ & 346.42 & 52.63 & 5.56 & 145.16 & 90.91 & 6.36 & 166.67 & 63.83 \\
\hline
\end{tabular}


Table 6. Average grain size in the base alloy, in the nugget and in the TMAZ of air-cooled and water-cooled AA6082 welds.

\begin{tabular}{|c|c|c|c|c|c|c|c|c|}
\hline & \multicolumn{8}{|c|}{ AA6082 } \\
\hline & \multicolumn{2}{|c|}{ Base alloy } & \multicolumn{6}{|c|}{ FSW } \\
\hline & & \multirow[b]{3}{*}{$\perp$} & \multicolumn{3}{|c|}{ Air-cooled } & \multicolumn{3}{|c|}{ Water-cooled } \\
\hline & \multirow[b]{2}{*}{$/ /$} & & Nugget & \multicolumn{2}{|c|}{ TMAZ } & \multirow[t]{2}{*}{ Nugget } & \multicolumn{2}{|c|}{ TMAZ } \\
\hline & & & & $/ /$ & $\perp$ & & $/ /$ & $\perp$ \\
\hline $\mathrm{n}_{\mathrm{i}}$ & 9.33 & 14.33 & 45.33 & 11.33 & 16.67 & 34.00 & 13.00 & 13.00 \\
\hline $\begin{array}{c}\mathbf{n}_{\mathrm{i}} \text { standard } \\
\text { deviation }\end{array}$ & 1.53 & 1.53 & 5.13 & 1.15 & 1.15 & 3.61 & 1 & 1 \\
\hline$A_{\text {int }}$ & 32.15 & 13.96 & 2.21 & 26.47 & 12.00 & 2.94 & 23.08 & 15.38 \\
\hline $\mathrm{d}[\mu \mathrm{m}]$ & 160.77 & 69.78 & 5.51 & 132.35 & 60.00 & 7.35 & 115.38 & 76.92 \\
\hline
\end{tabular}

Table 7. Average grain size in the base alloy, in the nugget and in the TMAZ of air-cooled and water-cooled AA7075 welds.

\begin{tabular}{|c|c|c|c|c|c|c|c|c|}
\hline & \multicolumn{8}{|c|}{ AA7075 } \\
\hline & \multicolumn{2}{|c|}{ Base alloy } & \multicolumn{6}{|c|}{ FSW } \\
\hline & & \multirow[b]{3}{*}{$\perp$} & \multicolumn{3}{|c|}{ Air-cooled } & \multicolumn{3}{|c|}{ Water-cooled } \\
\hline & \multirow[b]{2}{*}{$/ /$} & & Nugget & \multicolumn{2}{|c|}{ TMAZ } & \multirow[t]{2}{*}{ Nugget } & \multicolumn{2}{|c|}{ TMAZ } \\
\hline & & & & $/ /$ & $\perp$ & & $/ /$ & $\perp$ \\
\hline $\mathbf{n}_{\mathrm{i}}$ & 6.3 & 20.67 & 39.33 & 10.33 & 26.00 & 36.33 & 13.67 & 24.33 \\
\hline $\begin{array}{l}\text { ni standard } \\
\text { deviation }\end{array}$ & 2.52 & 0.58 & 3.51 & 2.31 & 4.58 & 1.15 & 2.89 & 2.08 \\
\hline$A_{\text {int }}$ & 47.62 & 9.68 & 2.54 & 29.03 & 7.69 & 2.75 & 21.95 & 8.22 \\
\hline $\mathrm{d}[\mu \mathrm{m}]$ & 238.10 & 48.38 & 6.36 & 145.16 & 38.46 & 6.88 & 109.76 & 41.10 \\
\hline
\end{tabular}

\subsection{Rockwell and Vickers Hardness Distributions}

Figure 11 shows the area where the Rockwell hardness were measured.

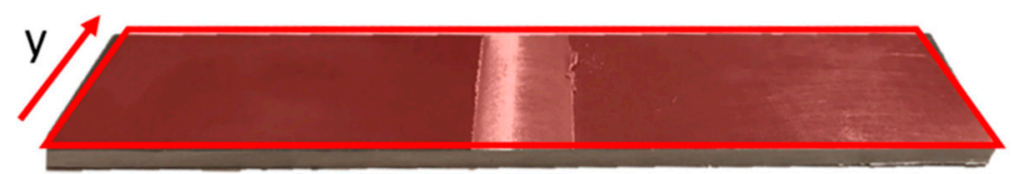

Figure 11. Specimen surface on which Rockwell hardness tests were performed.

The distributions of Rockwell hardness measured on the top of the specimens are reported in Figure 12. 

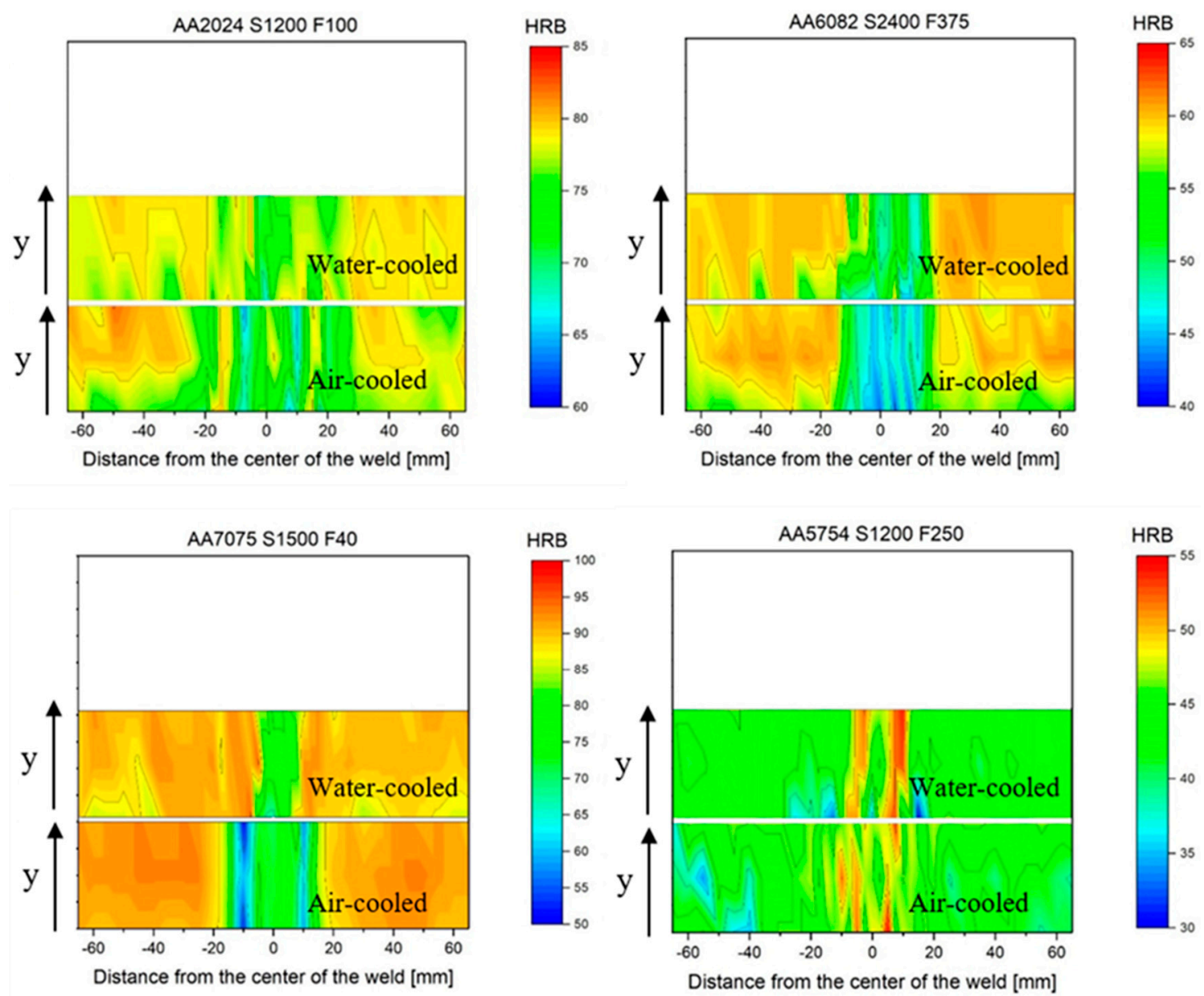

Figure 12. Rockwell hardness maps.

Figure 13 shows the area where the Vickers hardness were measured. The distributions of the hardness measured along the transversal section for the different cases considered are reported in Figure 14 .

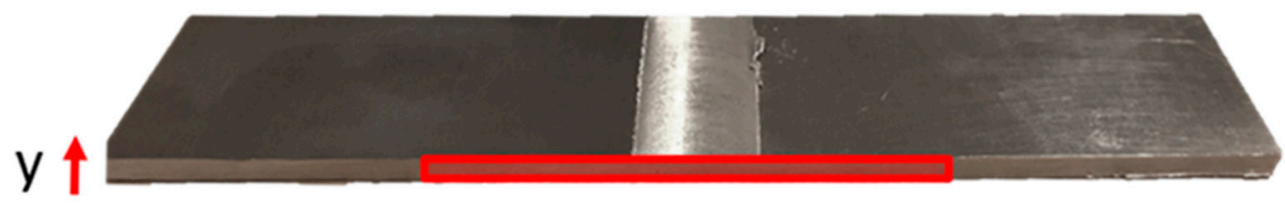

Figure 13. Specimen surface on which Vickers hardness tests were performed.

\subsection{Tensile Tests}

The ultimate tensile strength (UTS), elongation (A) [\%] and their standard deviation, calculated for all the alloys and for all the tested conditions according to the type of cooling, are reported in Table 8 . 

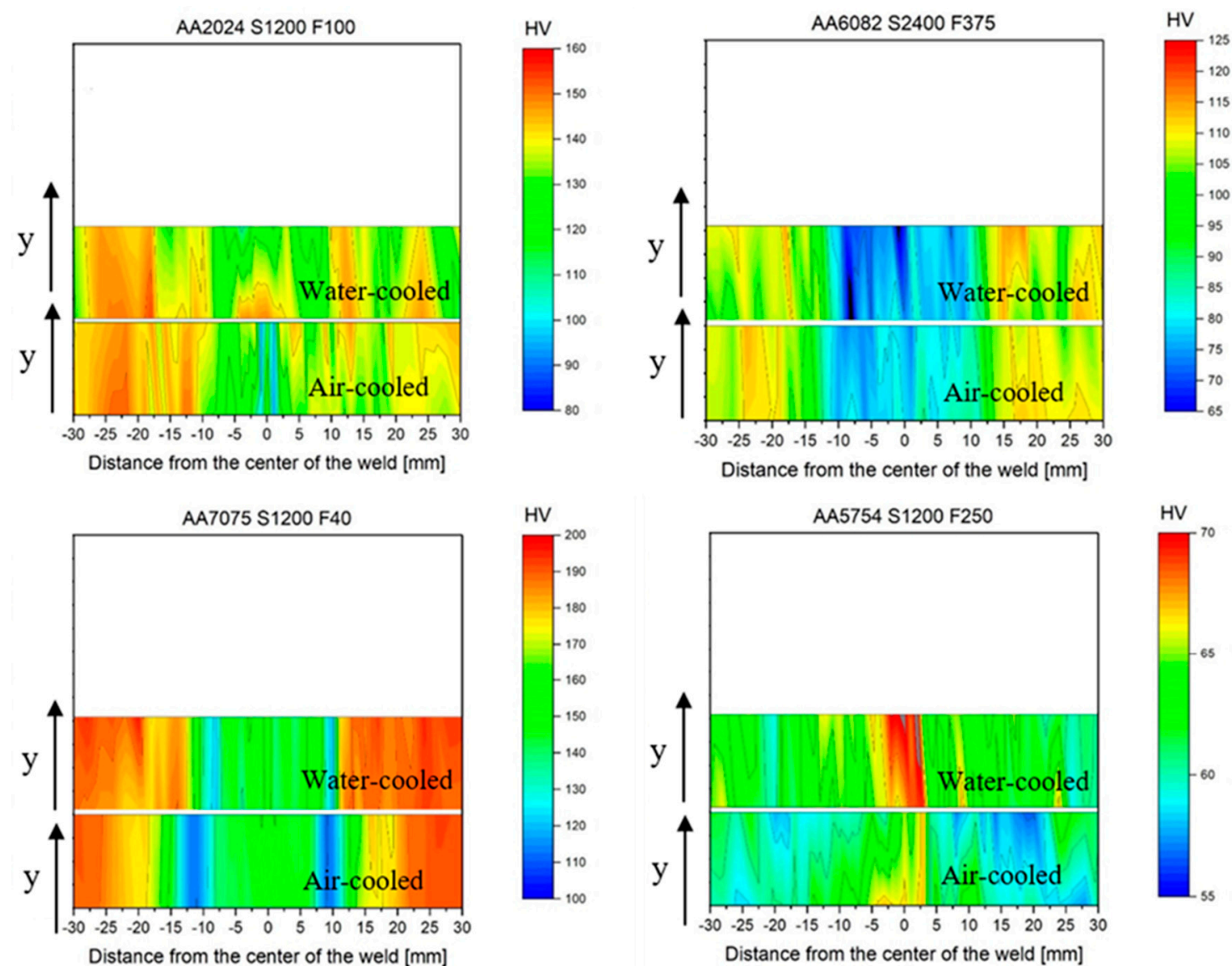

Figure 14. Vickers hardness maps.

Table 8. Average ultimate tensile strength (UTS) data, real elongation (A) and standard deviations of all the tested conditions.

\begin{tabular}{cccccc}
\hline \multirow{2}{*}{ Alloy } & UTS [MPa] & $\begin{array}{c}\text { UTS Standard } \\
\text { Deviation [MPa] }\end{array}$ & A [\%] & $\begin{array}{c}\text { A Standard } \\
\text { Deviation [\%] }\end{array}$ \\
\hline \multirow{2}{*}{ AA2024 } & Air-cooled & 289.59 & 17.24 & 0.91 & 0.28 \\
\cline { 2 - 6 } & Water-cooled & 278.23 & 22.79 & 1.11 & 0.31 \\
\hline \multirow{2}{*}{ AA6082 } & Air-cooled & 220.73 & 3.62 & 3.91 & 0.47 \\
\cline { 2 - 6 } & Water-cooled & 217.27 & 6.06 & 2.62 & 0.21 \\
\hline \multirow{2}{*}{ AA7075 } & Air-cooled & 352.46 & 44.02 & 0.96 & 0.87 \\
\cline { 2 - 6 } & Water-cooled & 370.33 & 40.71 & 2.16 & 1.34 \\
\hline \multirow{2}{*}{ AA5754 } & Air-cooled & 198.80 & 8.07 & 14.11 & 4.47 \\
\cline { 2 - 6 } & Water-cooled & 201.21 & 4.39 & 17.36 & 2.01 \\
\hline
\end{tabular}

The UTS and elongation data obtained from the tensile tests for the different cases are reported in Figure 15 for analyzing the effect of the cooling system. 

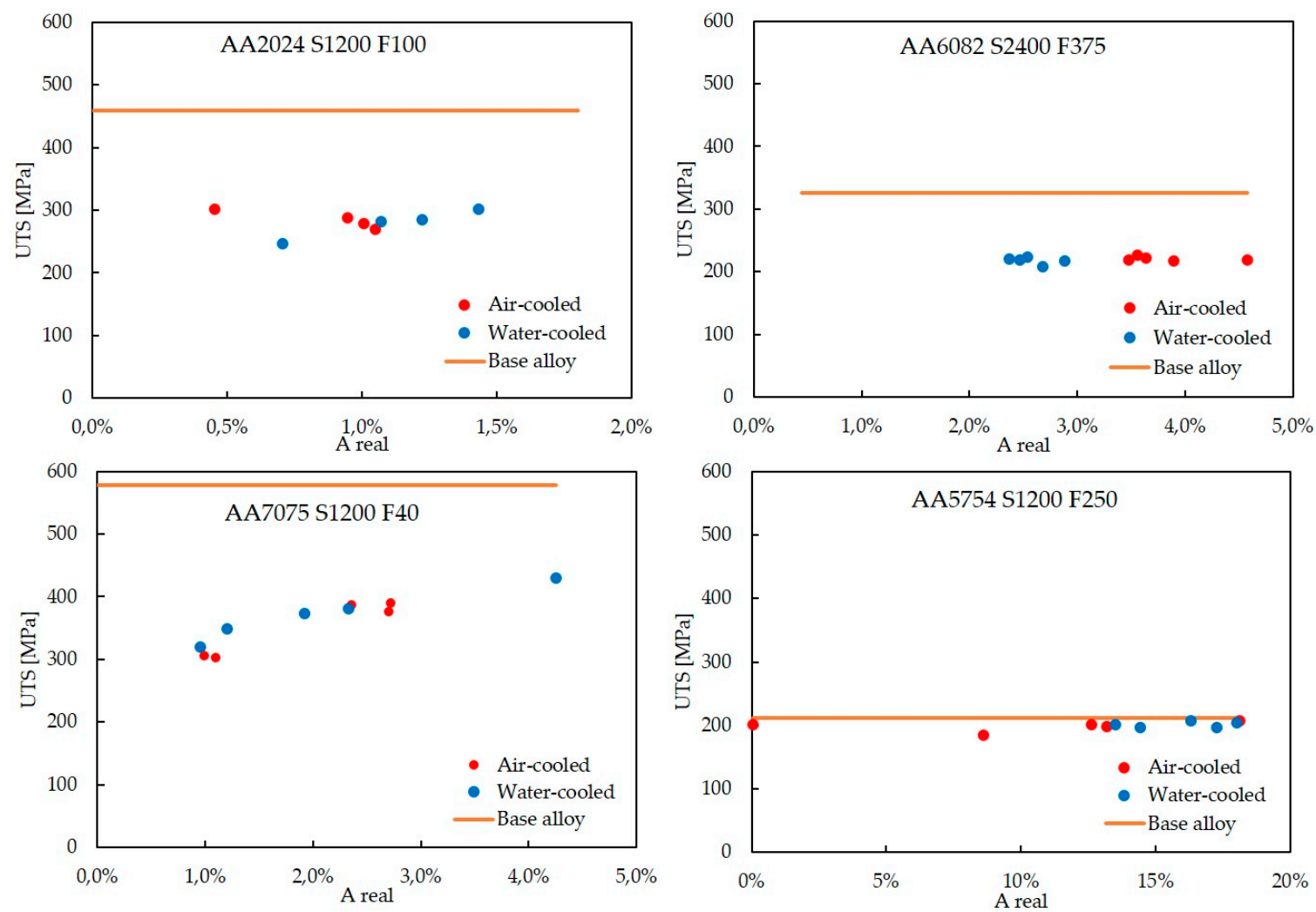

Figure 15. Ultimate tensile strength (UTS) versus elongation [\%] data obtained from tensile tests for all the alloys and for all the tested conditions. The continuous line indicates the UTS value of the base alloy.

Figure 16 reports the fracture locations on the tensile test specimens for each alloy and for each cooling condition. The reported images refer to the most representative situation of each condition drawing a direct comparison between the different cooling methods. It is possible to observe that, for each studied condition, the break occurred near the welding, while the only substantial difference is represented by the water-cooled welding of the AA5754.
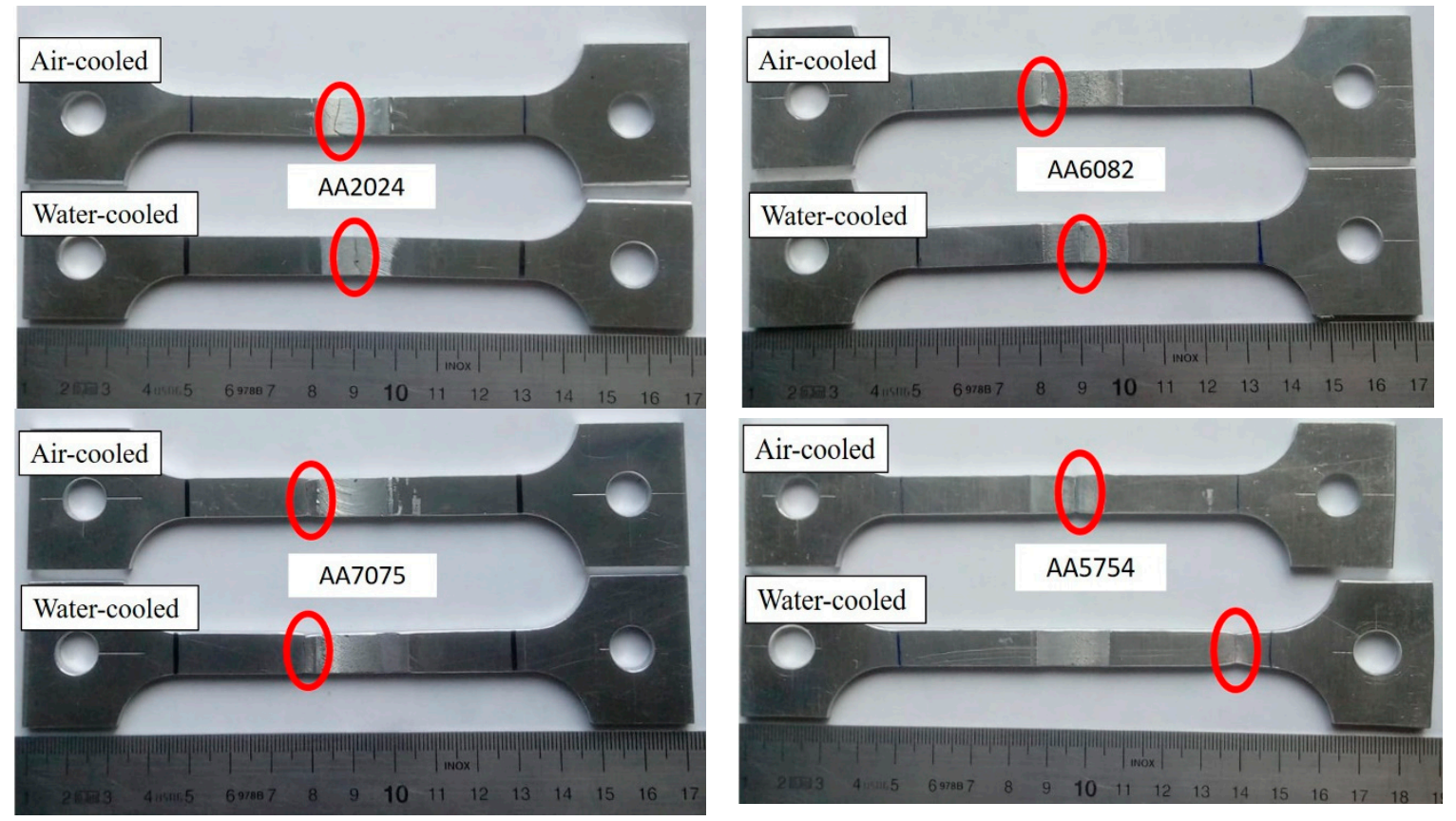

Figure 16. Fracture location for each alloy and for each cooling condition. 


\section{Discussion}

The alloys belonging to the $2 x x x$ series are normally supplied in the T3 or T4 state, abbreviations indicating respectively solubilization and natural aging heat treatment. The T3 heat treatment involves a cold processing step between solubilization and aging. The cold plastic deformation allows to obtain superior mechanical properties compared to aging alone.

Natural aging involves maintaining the alloy for a long time, at room temperature or at a slightly higher temperature. During this period, there is the spontaneous formation of a structure characterized by the presence of Guinner-Preston zones (G.P.), which are areas of the crystalline matrix where the clusters of precipitates and solutes are aggregated. The areas thus formed oppose greater resistance to the path of the dislocations than the crystalline matrix of the base metal, generating the desired increase in mechanical strength.

Natural aging appears to be an extremely slow process and, for some alloys, such as those belonging to the $6 x x x$ and $7 x x x$ series, it does not guarantee the achievement of stable conditions.

For this reason, the AA6082 to AA7075 alloys are usually supplied in the T6 state, which provides solubilization, tempering and artificial aging.

Artificial aging involves exposing the alloy to temperatures above room temperature for obtaining the transition phase starting from the equilibrium precipitates; this form of transition remains consistent with the matrix of the solid solution and therefore contributes to precipitation-hardening. However, as the aging temperature increases, the precipitate particles grow and reconvert to the state of equilibrium, which is generally inconsistent. These changes produce a loss of mechanical characteristics with respect to the untreated base metal. This phenomenon is called over-aging.

The control of the temperatures to which these alloys are subjected is therefore of fundamental importance for the mechanical properties of both the base material and the friction stir welded one. Consequently, the presence of a water-cooling system plays a key role in controlling the thermal cycle to which these alloys are subjected during welding. Furthermore, each point of the weld, in relation to its distance from the center of the nugget, has a microstructure strongly influenced by the welding process.

Therefore, in the weld region, where the material is stirred at solid-state, dissolution, coarsening of strengthening precipitates and formation of wide precipitate free zone take place.

From the measurements made on the joints, a clear dependence of the average grain size from the cooling system is detectable. In particular, in the water-cooled nugget, the grains are characterized by an increase in the average size compared to the air-cooled nugget being 14\% in AA2024 (Table 5), 33\% in AA6082 (Table 6) and 8\% in AA7075 (Table 7). It is possible to notice how the percentage growth of the average dimensions present in the nuggets of the single alloys, is significantly different from each other. This is attributable to the mechanical characteristics of the base alloys. In fact, hardness and mechanical strength of AA7075 result in greater resistance to the breakage action of the grains by the pin. This is also reflected by the average size of the grains present in its air-cooled welded nugget, which are already on average larger than those present in the other two alloys (Figure 8).

On the contrary, the alloy with the highest percentage growth is the AA6082, which has the mechanical characteristics on average lower than the other two alloys and it is also characterized by grains with average lower dimensions in the air-cooled welded nugget (Figure 7).

Regarding the TMAZs, AA6082 and AA7075 show grains characterized by smaller average dimensions in the rolling direction in water-cooled welds. Contrariwise, perpendicularly to the rolling direction, in water-cooled joints, the grains are slightly larger (Figures 7 and 8 ). The percentage decrease was around 13\% in AA6082 and 25\% in AA7075 parallel to the rolling direction. The percentage increase perpendicularly to the rolling direction was about 28\% in AA6082 and 7\% in AA7075 (Tables 6 and 7). These dimensional variations make the grains present in water-cooled welds smaller than those present in the same position for air-cooled welds.

On the contrary, in AA2024, the average grain size increases by $15 \%$ in the direction parallel to the rolling direction and decreases by $30 \%$ in the perpendicular direction (Table 5). 
As a general observation, it can be seen that in each alloy, the grain size in the TMAZ is much closer to that of the base material in the direction perpendicular to the rolling direction in water-cooled welds. In the case of AA6082, perpendicularly to the rolling direction, the water-cooled TMAZ grains are characterized by an average size even greater than those of the base alloy. This is further proof of how the material responds differently to the cooling system in microstructural terms and, consequently, in the mechanical characteristics.

In fact, from the mechanical tests data, it is possible to observe a behavior common to all the precipitation-hardening alloys (AA2024, AA6082, and AA7075). In particular, for all the welded conditions, the specimens have specific zones characterized by hardness lower than the one of the base materials. This characteristic trend of the hardness values in precipitation-hardening alloys is mainly due to the thermo-mechanical action of the pin that acts on the alloy modifying its microstructural characteristics.

In fact, for these alloys, it is possible to identify a clear microstructural change caused by the welding process (Figures 6-8). The heat generation and the mechanical action of the stirring generate a dynamic recrystallization that particularly affects the nugget. In TMAZs, the dynamic action of the pin and the heat generated are not sufficient to modify the microstructure of the base material. Therefore, in these zones, the grains are similar to the original ones (Figure 5) maintaining an elongated shape along the rolling direction (Figure $6 c, d$, Figure $7 c, d$ and Figure $8 c, d$ ).

Even the precipitates are influenced by the FSW process in two ways. In fact, depending on the action of the pin and the heat input, it is possible to have both the crushing of large precipitates by the mechanical action and the coalescence of the precipitates in sub-micrometric dimensions.

These are the reasons why the lower hardness areas are concentrated in the TMAZs, where the grain recrystallization is not complete and where the alloy-hardening-precipitates are partially crushed. On the other hand, in the nugget, the dynamic recrystallization is complete and the precipitates are fully crushed reaching the sub-micrometric dimensions suitable for strengthening the matrix formed by the micrometric grains (Figure $6 a, b$, Figure $7 a, b$ and Figure $8 a, b$ ).

Besides, AA5754 presents a completely different behavior and a different hardness map. In fact, since AA5754 is a work-hardening alloy, the thermo-mechanical action of the pin has led to a hardness increase in the nugget area, where the solid-state mixing has completely taken place.

By comparing the hardness maps measured on air-cooled and water-cooled welds, it is possible to observe how the effect of water-cooling is twofold on each alloy (Figures 11 and 13). The first effect can be traced in the numerical value of the hardness achieved in the TMAZs, as regards the three precipitation-hardening alloys and in the nugget for the work-hardening alloy. In these areas, for all the alloys and for all the considered conditions, the hardness is higher than those measured in air-cooled welds. This effect is less noticeable on AA2024 joint. Moreover, AA6082 Rockwell tests showed an increase in the hardness values at the nugget in water-cooled welds.

The second effect is the narrowing of the area characterized by the lower hardness values. Regarding the precipitation-hardening alloys, the extent of the zone characterized by the lower hardness is considerably reduced in the water-cooled specimens. On the contrary, in AA5754, the extent of the area characterized by a greater hardness is almost constant for air-cooled and water-cooled welds (Figures 11 and 13).

These effects are mainly due to the presence of the local water-cooling during the welding process that leads to a better dimensional control of the grains in the joints, which is closely related to the mechanical properties of the piece.

Also, the hardness is closely related to the microstructure of the materials. As a consequence, it is possible to correlate the increase in hardness in the TMAZ of AA6082 and AA7075 welded with the water-cooling system to the smaller dimensions of the grain present in these areas. On the contrary, it has already been noted that AA2024 has mitigated the effect in increasing the hardness in the TMAZ of water-cooled welds. This characteristic of AA2024 finds its explanation in the further elongation that the grains undergo in the TMAZ of water-cooled welds, as reported in Section 3.1. 
By observing the Vickers hardness maps (Figure 13), it is possible to draw the same considerations made for the Rockwell hardness maps (Figure 11). In fact, it is possible to notice, also in the cross-section of the specimens, an increase in the hardness in the central areas of the specimens, except for AA6082, and a reduction in the extent of the area characterized by lower hardness values for the hardening alloys. Concerning the AA6082, the decrease in Vickers hardness recorded in the cross-section could be related to the considerable increase in the average grain size at the nugget of the water-cooled welds. In fact, this alloy has proved to have the highest average percentage growth rate of the grains present in the water-cooled weld nugget, as already reported in Table 6. Finally, it is possible to observe, for AA5754, a significant increase in the hardness values in correspondence of the nugget.

Also, in the tensile tests, it is possible to observe different behaviors between the studied alloys (Figures 14 and 15). In particular, for the AA2024, the values of ultimate tensile strength and percentage of elongation are almost comparable for both cooling methods and are much lower than those of the base metal. Both cooling conditions led to breakages in the nugget during the tensile tests.

In regard to the tensile tests of the AA6082, the average values of UTS and percentage elongation are comparable between air-cooled and water-cooled welds. But the cooling system seems to affect the fracture locations of the tested joints. In fact, the air-cooled joints showed fractures at the interface between the nugget and TMAZ, while the water-cooled joints broke especially at the nugget. Moreover, the AA7075 has shown a benefit in water-cooling in the UTS but both cooling conditions led to breakages in the interface between the nugget and TMAZ during the tensile tests.

However, it is possible to recognize the welding obtained from the AA5754 joints as the welding that has reached the value of UTS and of percentage elongation closer to those of the base alloy both in the air-cooled and water-cooled process. Finally, for this work-hardening alloy, the percentage elongation was found to be on average higher for water-cooled welds than those air-cooled and, in particular, it was possible to observe that in the water-cooled joints the point of failure is placed in the base material, away from the welded area. On the contrary, in the air-cooled joints, the breakages were found in the nugget. This peculiarity of AA5754 could be explained by the benefit that a water-cooling performed during the friction stir processing would lead to a work-hardening aluminum alloy.

\section{Conclusions}

The paper reports the results of the investigations of the effect of a water-cooling system on the mechanical properties and microstructural characteristics on FSW joints made of different alloys: precipitation-hardening alloys AA2024-T3, AA6082-T6 and AA7075-T6, and work-hardening alloy AA5754-H111. All these alloys showed a different behavior. In fact, AA2024 proved to be the least affected by the cooling system. Moreover, a clear dependence between the cooling systems and the average value of percentage elongation was detectable in AA6082, although the Rockwell tests showed an increase in the hardness values at the nugget in water-cooled welds. The AA7075 alloy was characterized by an increase in hardness distributions and an improvement in the breaking load in water-cooled welded joints. Regarding the AA5754, it reached the value of UTS and of percentage elongation closer to those of the base alloy both in the air-cooled and water-cooled process; it was possible to observe that only in the water-cooled joints, the point of failure is placed in the base material, away from the welded area.

Author Contributions: Conceptualization, S.B., G.D. and C.G.; methodology, S.B. and G.D.; formal analysis, S.B., G.D. and C.G.; investigation, S.B. and G.D.U.; data curation, S.B.; writing-original draft preparation, S.B. and G.D.U.; writing-review and editing, S.B., G.D., C.G. and G.M.; visualization, S.B. and G.D.U.; supervision, C.G.

Funding: This research received no external funding.

Conflicts of Interest: The authors declare no conflict of interest. 


\section{References}

1. Chen, R.; Xu, Q.; Guo, H.; Xia, Z.; Wu, Q.; Liu, B. Modeling the precipitation kinetics and tensile properties in Al-7Si-Mg cast aluminum alloys. Mater. Sci. Eng. 2017, 685, 403-416. [CrossRef]

2. Alexopoulos, N.D.; Velonaki, Z.; Stergiou, C.I.; Kourkoulis, S.K. Effect of ageing on precipitation kinetics, tensile and work hardening behavior of Al-Cu-Mg (2024) alloy. Mater. Sci. Eng. 2017, 700, 457-467. [CrossRef]

3. Wang, W.; Wang, G.; Hu, Y.; Guo, G.; Zhou, T.; Rong, Y. Temperature-dependent constitutive behavior with consideration of microstructure evolution for as-quenched Al-Cu-Mn alloy. Mater. Sci. Eng. 2016, 678, 85-92. [CrossRef]

4. Feng, Z.; Yang, Y.; Huang, B.; Han, M.; Luo, X.; Ru, J. Precipitation process along dislocations in Al-Cu-Mg alloy during artificial aging. Mater. Sci. Eng. 2010, 528, 706-714. [CrossRef]

5. Armstrong, R.W. The influence of polycrystal grain size on several mechanical properties of materials. Metall. Mater. Trans. 1970, 1, 1169-1176. [CrossRef]

6. Threadgill, P.L.; Leonard, A.J.; Shercliff, H.R.; Withers, P.J. Friction stir welding of aluminium alloys. Int. Mater. Rev. 2009, 54, 49-93. [CrossRef]

7. El-Danaf, E.A.; El-Rayes, M.M. Microstructure and mechanical properties of friction stir welded 6082 AA in as welded and post weld heat treated conditions. Mater. Des. 2013, 46, 561-572. [CrossRef]

8. Sonne, M.R.; Tutum, C.C.; Hattel, J.H.; Simar, A.; De Meester, B. The effect of hardening laws and thermal softening on modeling residual stresses in FSW of aluminum alloy 2024-T3. J. Mater. Process. Technol. 2013, 213, 477-486. [CrossRef]

9. Martinsen, K.; Hu, S.J.; Carlson, B.E. Joining of dissimilar materials. CIRP Ann. Manuf. Technol. 2015, 64, 679-699. [CrossRef]

10. Rhodes, C.G.; Mahoney, M.W.; Bingel, W.H.; Spurling, R.A.; Bampton, C.C. Effects of friction stir welding on microstructure of 7075 aluminum. Scr. Mater. 1997, 36, 69-75. [CrossRef]

11. Mishra, R.S.; Ma, Z.Y. Friction stir welding and processing. Mater. Sci. Eng. Rep. 2005, 50, 1-78. [CrossRef]

12. Mishra, R.S.; De, P.S.; Kumar, N. Friction Stir Welding and Processing, 1st ed.; Springer International Publishing: Berlin, Germany, 2014; pp. 13-58.

13. Bocchi, S.; Cabrini, M.; D’Urso, G.; Giardini, C.; Lorenzi, S.; Pastore, T. The influence of process parameters on mechanical properties and corrosion behavior of friction stir welded aluminum joints. J. Manuf. Process. 2018, 35, 1-15. [CrossRef]

14. Upadhyay, P.; Reynolds, A.P. Effects of thermal boundary conditions in friction stir welded AA7050-T7 sheets. Mater. Sci. Eng. 2010, 527, 1537-1543. [CrossRef]

15. Di, S.; Yang, X.; Luan, G.; Jian, B. Comparative study on fatigue properties between AA2024-T4 friction stir welds and base materials. Mater. Sci. Eng. 2006, 435-436, 389-395. [CrossRef]

16. Cabrini, M.; Lorenzi, S.; Bocchi, S.; Pastore, T.; D’Urso, G.; Giardini, C. Evaluation of corrosion behavior of AA2024 T3 welded. In Proceedings of the 20th International Corrosion Congress \& Process Safety Congress, Prague, Czech Republic, 3-7 September 2017; pp. 1-15.

17. Moradi, M.M.; Jamshidi Aval, H.; Jamaati, R. Effect of pre and post welding heat treatment in SiC-fortified dissimilar AA6061-AA2024 FSW butt joint. J. Manuf. Process. 2017, 30, 97-105. [CrossRef]

18. Kosturek, R.; Śniezek, L.; Wachowski, M.; Torzewski, J. The influence of post-weld heat treatment on the microstructure and fatigue properties of Sc-modified AA2519 friction stir-welded joint. Materials 2019, 12, 583. [CrossRef]

19. Safarbali, B.; Shamanian, M.; Eslami, A. Effect of post-weld heat treatment on joint properties of dissimilar friction stir welded 2024-T4 and 7075-T6 aluminum alloys. Trans. Nonferrous Met. Soc. China (Engl. Ed.) 2018, 28, 1287-1297. [CrossRef]

20. Wahid, M.A.; Khan, Z.A.; Siddiquee, A.N. Review on underwater friction stir welding: A variant of friction stir welding with great potential of improving joint properties. Trans. Nonferrous Met. Soc. China (Engl. Ed.) 2018, 28, 193-219. [CrossRef]

21. Zeng, X.H.; Xue, P.; Wu, L.H.; Ni, D.R.; Xiao, B.L.; Wang, K.S.; Ma, Z. Microstructural evolution of aluminum alloy during friction stir welding under different tool rotation rates and cooling conditions. J. Mater. Sci. Technol. 2019, 35, 972-981. [CrossRef] 
22. Lin, H.; Wu, Y.; Liu, S.; Zhou, X. Effect of cooling conditions on microstructure and mechanical properties of friction stir welded 7055 aluminium alloy joints. Mater. Charact. 2018, 141, 74-85. [CrossRef]

23. Singh, R.K.R.; Prasad, R.; Pandey, S.; Sharma, S.K. Effect of cooling environment and welding speed on fatigue properties of friction stir welded Al-Mg-Cr alloy. Int. J. Fatigue 2019, 127, 551-563. [CrossRef]

24. Simar, A.; Bréchet, Y.; de Meester, B.; Denquin, A.; Pardoen, T. Microstructure, local and global mechanical properties of friction stir welds in aluminium alloy 6005A-T6. Mater. Sci. Eng. 2008, 486, 85-95. [CrossRef]

25. Dong, P.; Li, H.; Sun, D.; Gong, W.; Liu, J. Effects of welding speed on the microstructure and hardness in friction stir welding joints of 6005A-T6 aluminum alloy. Mater. Des. 2013, 45, 524-531. [CrossRef]

26. Fratini, L.; Buffa, G.; Shivpuri, R. Mechanical and metallurgical effects of in process cooling during friction stir welding of AA7075-T6 butt joints. Acta Mater. 2010, 58, 2056-2067. [CrossRef]

27. Xu, W.F.; Liu, J.H.; Chen, D.L.; Luan, G.H.; Yao, J.S. Improvements of strength and ductility in aluminum alloy joints via rapid cooling during friction stir welding. Mater. Sci. Eng. 2012, 548, 89-98. [CrossRef]

28. Cho, J.H.; Han, S.H.; Lee, C.G. Cooling effect on microstructure and mechanical properties during friction stir welding of Al-Mg-Si aluminum alloys. Mater. Lett. 2016, 180, 157-161. [CrossRef]

29. Radisavljevic, I.; Zivkovic, A.; Radovic, N.; Grabulov, V. Influence of FSW parameters on formation quality and mechanical properties of Al 2024-T351 butt welded joints. Trans. Nonferrous Met. Soc. China (Engl. Ed.) 2013, 23, 3525-3539. [CrossRef]

30. Zhang, Z.; Yang, X.; Zhang, J.; Zhou, G.; Xu, X.; Zou, B. Effect of welding parameters on microstructure and mechanical properties of friction stir spot welded 5052 aluminum alloy. Mater. Des. 2011, 32, 4461-4470. [CrossRef]

31. Venugopal, T.; Rao, K.S.; Rao, K.P. Studies on friction stir welded AA 7075 aluminum alloy. Trans. Indian Inst. Met. 2004, 57, 659-663.

32. Prasad, M.V.R.D.; Namala, K. Process parameters optimization in friction stir welding by ANOVA. Mater. Today Proc. 2018, 5, 4824-4831. [CrossRef]

33. Rajakumar, S.; Muralidharan, C.; Balasubramanian, V. Optimization of the friction-stir-welding process and tool parameters to attain a maximum tensile strength of AA7075-T6 aluminium alloy. Proc. Inst. Mech. Eng. Part B J. Eng. Manuf. 2010, 224, 1175-1191. [CrossRef]

(C) 2019 by the authors. Licensee MDPI, Basel, Switzerland. This article is an open access article distributed under the terms and conditions of the Creative Commons Attribution (CC BY) license (http://creativecommons.org/licenses/by/4.0/). 